\title{
Formação continuada do coordenador pedagógico
}

\author{
Continued training of the pedagogical coordinator
}

Jerônimo Sartori ${ }^{1}$

Altair Alberto Fávero²

\section{Resumo}

O estudo reflete sobre a "formação continuada do coordenador pedagógico", que atua em escolas vinculadas à $15^{\mathrm{a}}$ Coordenadoria Regional de Educação (CRE) - Erechim, RS. A referida formação ocorreu em um curso de Extensão de 60 horas, realizado em 2018-2019, na Universidade Federal da Fronteira Sul (UFFS), Campus Erechim. O objetivo do estudo é "analisar de que modo o curso de formação continuada possibilitou o fortalecimento da relação entre coordenador e coordenados na escola". O estudo está embasado no aprofundamento teórico sobre o tema e na análise do material empírico, obtido por meio de um questionário respondido pelos coordenadores. A análise crítica da empiria configurou-se em três categorias: a compreensão sobre a função do coordenador pedagógico; o trabalho do coordenador pedagógico na escola; os desafios e os limites da ação coordenadora na escola. Ao finalizar o estudo ficou tácito que a formação fortaleceu a ação coordenadora, com destaque à troca de experiências entre os coordenadores e destes com os professores da universidade. Os diálogos evidenciaram

${ }^{1}$ Licenciado em Ciências - LC (UPF) e Biologia - LP (UnC), Especialização em Supervisão Escolar (UPF), Mestrado em Educação (PPGEdu/PUCRS), Doutorado em Educação (PPGEdu/Faced/UFRGS), estágio Pós-doutoral em Educação (PPGEdu/Faed/UPF). Professor dos cursos: Pedagogia (LP), Educação do Campo (LP) e Mestrado Profissional em Educação (PPGPE/UFFS). Campus Erechim, Universidade Federal da Fronteira Sul.

${ }^{2}$ Coordenador do PPGEDU/UPF (gestão 2019-2021)

Professor do Curso de Filosofia, Mestrado e Doutorado em Educação - UPFPesquisador da Linha de Políticas Educacionais

Pós-Doc UAEM/México (Bolsista Capes)Doutor em Educação (UFRGS)Mestre em Filosofia (PUCRS)Especialista em Epistemologia das Ciências SociaisGraduado em Filosofia e História

Interfaces da Educ., Paranaíba, v.11, n.32, p. 34 - 59, 2020

ISSN 2177-7691

Recebido em 08 de março 2020 e aceito em 28 de abril de 2020 
algumas fragilidades, que entravam o trabalho do $\mathrm{CP}$, especialmente, referente às frágeis condições de trabalho que remetem ao desvio das atribuições específicas, de assessoramento e de dinamizador da formação continuada dos docentes na escola.

Palavras-chave: Formação Continuada. Processo Pedagógico. Coordenador Pedagógico.

\section{Abstract}

The study reflects on the "continued formation of the pedagogical coordinator", who operates in schools linked to the 15th Regional Education Coordination (CRE) - Erechim, RS. This training took place in a 60-hour extension course, held in 2018-2019, at Universidade Federal da Fronteira Sul (UFFS), Campus Erechim. The aim of the study is "to analyze how the continuing education course has enabled the strengthening of the relationship between coordinator and coordinated staff at school". The study is based on the theoretical study on the subject and on the analysis of empirical material, obtained through a questionnaire answered by the coordinators. The critical analysis of 'empiria' was configured in three categories: the understanding of the function of the pedagogical coordinator; the work of the pedagogical coordinator at school; the challenges and limits of coordinating action at school. At the end of the study, it was tacit that the training strengthened the coordinating action, with emphasis on the exchange of experiences between the coordinators, and these ones with the professors. The dialogues highlighted some weaknesses, which hinder the work of the pedagogical coordinators, especially regarding the fragile working conditions related to the deviation of the specific attributions, of the counselling and facilitating of the teachers' continuing education in the school.

Interfaces da Educ., Paranaíba, v.11, n.32, p. 34 - 59, 2020 
Keywords: Continued Training. Pedagogical Process. Pedagogical Coordinator.

\section{A título de introdução}

A educação escolar no Brasil ainda carece de reafirmação sobre o seu papel social, ficando o desafio de construir a escola que efetivamente atenda às demandas de uma sociedade democrática, que universalize o acesso à educação básica e garanta acesso, permanência e sucesso escolar. Para tanto, entende-se, como imprescindivel, a formação continuada dos profissionais da educação, tanto da equipe de gestores como dos docentes.

Neste estudo, o recorte recai sobre a formação continuada dos profissionais da educação que exercem a coordenação pedagógica na escola. A concepção de coordenação pedagógica que se entrecruza, neste artigo, ancora-se na ideia de que o trabalho do Coordenador Pedagógico (CP) desenvolve-se por meio do estabelecimento de relações horizontais, amistosas e democráticas entre coordenador e professores. $\mathrm{O}$ estabelecimento de parcerias e um clima de mútua confiança necessita ser construído, haja vista o embaraço que ainda paira sobre a atuação deste profissional, que se origina na inspeção e supervisão escolar com atuação meramente burocrática, controladora e fiscalizadora.

Para situar o trabalho do CP é necessário tecer algumas considerações sobre como, historicamente, este sujeito atuou nos sistemas e nas escolas. Ao considerar o tempo histórico, a função do Supervisor Educacional (SE) deriva do Ratio Studiorum implantado pela Companhia de Jesus em 1552, prevendo a figura do prefeito geral, que tinha a função de auxiliar o reitor na ordenação dos estudos, a quem professores e alunos deveriam obedecer (SAVIANI, 2015). Portanto, é do Ratio Studiorum que nasce a ideia de supervisão educacional, que abarcava "os aspectos de direção, fiscalização, coordenação e orientação do ensino" (SAVIANI, 2015, p. 24). 
No período de 1860-1890, emerge a demanda pelo fortalecimento da articulação dos serviços educacionais em razão da necessidade de organização "de um sistema nacional de educação" (SAVIANI, 2015, p. 25). Naquele periodo, a ideia de supervisão ganha contornos mais claros, abrindo perspectivas para a configuração do estatuto da prática supervisora (SAVIANI, 2015). Assim, no âmbito de algumas escolas, o serviço de supervisão adquire a conotação de coordenação das atividades pedagógicas, considerando que o caráter fiscalizador ao gerar reações contrárias aos professores produz prejuízos nas relações interpessoais e no desempenho da docência.

$\mathrm{Na}$ década de 1920, com o advento do tema "profissionais da educação", surgem os "técnicos da educação", tornando-se uma nova categoria profissional (SAVIANI, 2015). Ao instituir órgãos próprios de "administração do ensino", há o encaminhamento para a separação dos setores técnico-pedagógicos dos administrativos, constituindo a "condição para o surgimento da figura do supervisor como distinta do diretor e também do inspetor" (SAVIANI, 2015, p. 28). Naquele momento, no estado de São Paulo, por exemplo, o supervisor que atuava na escola passou a receber a denominação de "coordenador pedagógico".

Na década de 1960, com a aprovação da Lei de Diretrizes e Bases da Educação Nacional (LDB) - Lei no 4024/61 e com o golpe de 19641', na Reforma Universitária - Lei ${ }^{\circ} 5540 / 1968$, acontecem algumas mudanças no ensino. O Parecer $n^{\circ}$ 252/69 do Conselho Federal de Educação (CFE) reformula o curso de Pedagogia, introduzindo as habilitações: administração,

1 O Golpe Civil-Militar ocorreu em 31-03-1964, por meio de uma articulação golpista que instalou a Ditadura Militar no Brasil, regime que durou de 1964 até 1985. A Ditadura Militar deixou mazelas profundas à educação brasileira, entre elas, a expansão da educação básica com relativa qualidade e pouco investimento para a formação de professores, entre outras. Neste período houve a implementação da lei da reforma do ensino de $1^{\circ}$ e $2^{\circ}$ graus (Lei $n^{\circ} 5.692 / 71$ ), tornando obrigatório o ensino de $1^{\circ}$ grau com duração de 8 anos e o ensino de $2^{\circ}$ grau com duração de 3 anos e, com terminalidade profissionalizante para o ingresso no mercado de trabalho.

Interfaces da Educ., Paranaíba, v.11, n.32, p. 34 - 59, 2020 
inspeção, supervisão e orientação (SAVIANI, 2015). A formação no período teve caráter precipuamente tecnicista para garantir eficiência e produtividade ao processo educativo (SAVIANI, 2015). À medida que se problematiza a pretensa "neutralidade" do trabalho técnico dos especialistas, neste caso, do supervisor, avança-se na reflexão acerca da dimensão política do trabalho deste profissional da educação.

Durante o regime militar, também se aprovou a reforma do ensino de $1^{\circ}$ e $2^{\circ}$ grau - Lei $n^{\circ} 5692 / 71$, que enfatiza a necessidade do Supervisor Educacional com função de assessor, em vista da demanda de nova organização do ensino nas escolas. Diante disso, é atribuída ao supervisor educacional "[...] a tarefa de coordenação e orientação ao ensino oficial, fazendo com que a reforma do ensino possa ser implantada e conduzida em toda a plenitude de seu texto" (PRZYBYLSKI, 1982, p. 51). Embora com formação na perspectiva tecnicista, o SE representou um passo importante, pois, timidamente, alguns espaços iniciam ensaios de um trabalho orientado teoricamente e planejado conforme os princípios democráticos da participação e cooperação.

Em meados da década de 1980, com a redemocratização do país, avançou-se na discussão sobre a gestão educacional e escolar, ampliando a problematização do trabalho do $\mathrm{SE}$, que se realizava via através de práticas tecnicistas, burocráticas e controladoras (fiscalizadoras). No período, muitos sistemas de ensino e unidades escolares optaram por substituir a denominação SE por $\mathrm{CP}$, para enfrentar a ideia verticalizada no interior da escola de que "supervisão" significa "olhar de cima" ou "olhar fiscalizador". Sem a ingenuidade de acreditar que a mudança de denominação torna o trabalho mais fácil, a proposição é melhorar as relações interpessoais entre coordenador e coordenados, pelos princípios da ética e da mútua confiança.

A formação continuada é fundamental a todos os profissionais da educação ou áreas afins, implica ser entendida como processo permanente do vir a ser, ou seja, do ser e estar constantemente formando-se e 
reformando-se. Desse modo, considerando o contexto histórico em que se situa a função do $\mathrm{CP}$, procura-se, neste texto, tecer considerações sobre "como o processo formativo contribuiu para o aprimoramento da prática coordenadora no espaço escolar?", tendo, como objetivo principal, "analisar de que modo o curso de extensão formação continuada do Coordenador Pedagógico possibilitou o fortalecimento da relação entre coordenador e coordenados na escola"2.

O texto, além desta introdução e do itinerário do estudo, está organizado em mais três tópicos: a) aprofundamento da discussão a partir da empiria que aponta aspectos relevantes do processo formativo, considerando expectativas e contribuições do curso de formação continuada; b) discussão dos aspectos significativos desta etapa formativa de coordenadores pedagógicos, considerando os limites dos sujeitos envolvidos e do próprio curso; c) análise dos registros sobre o trabalho que o coordenador desenvolve na escola, bem como a relevância de planejar a ação coordenadora. E, ao final, apresenta-se uma síntese, considerando o olhar sobre o processo formativo e as possibilidades de desenvolver um trabalho participativo, colaborativo e democrático na escola.

\section{Itinerário do estudo}

O estudo trata da análise do processo formativo realizado em um curso de Extensão (60 horas) - Formação continuada de coordenadores pedagógicos, na Universidade Federal da Fronteira Sul (UFFS) - Campus Erechim, realizado em 15 encontros presenciais de 4 (quatro) horas em 2018-2019. No curso, realizaram-se estudos, debates e reflexões sobre: democratização da educação; planejamento educacional e curricular;

\footnotetext{
${ }^{2}$ A formação continuada do Coordenador Pedagógico ocorreu em um curso de Extensão de 60 horas, ofertado aos coordenadores pedagógicos das escolas vinculadas à $15^{\text {a }}$ Coordenadoria Regional de Educação (CRE) de Erechim - RS, realizado em 2018-2019, na Universidade Federal da Fronteira Sul (UFFS) - Campus Erechim.
}

Interfaces da Educ., Paranaíba, v.11, n.32, p. 34 - 59, 2020 
avaliação da aprendizagem; coordenação pedagógica e coordenador pedagógico: concepções, atribuições e limites da função.

Esta análise é de natureza eminentemente qualitativa, realizada por intermédio dos procedimentos da análise de conteúdo (BARDIN, 1977). O material empírico foi obtido por intermédio de um questionário com cinco questões, enviado aos 33 coordenadores pedagógicos que realizaram o curso, havendo retorno de 21 respondidos. Por meio do instrumento, buscou-se saber: o curso atendeu as expectativas; o curso trouxe contribuições para o trabalho na coordenação pedagógica; aspectos significativos e frágeis do curso; o trabalho do coordenador e o planejamento da ação coordenadora.

Os coordenadores que realizaram o curso são profissionais experientes em suas áreas de formação; na função de coordenador, a ampla maioria conta com atuação de até seis anos. A formação na graduação está distribuída: doze licenciados em Pedagogia, quatro Letras - Língua Portuguesa e Espanhol, dois Biologia, dois Geografia e um Matemática; todos possuem curso de especialização em áreas diversas. Estes coordenadores representam dezesseis escolas da região da $15^{\mathrm{a}}$ Coordenadoria Regional de Educação (CRE) - Erechim, possibilitando a análise da função coordenadora em diferentes escolas.

\section{Formação continuada do coordenador pedagógico: expectativas e contribuições}

Este estudo vincula-se ao curso de Extensão: Formação continuada de coordenadores pedagógicos, tendo como objetivo: "favorecer a construção de uma metodologia de trabalho na escola, que fortaleça a relação entre coordenador pedagógico e docentes, para que estes possam exercer a docência compromissados, política, pedagógica, técnica e eticamente"1. Neste inicio de seção, destaca-se a formação continuada, que "[...] se faz necessária pela própria natureza do saber e fazer como práticas que se transformam

\footnotetext{
${ }^{1}$ O objetivo do Projeto de Extensão submetido, UFFS/PROEC. Edital no 804/UFFS/2014. Interfaces da Educ., Paranaíba, v.11, n.32, p. 34 - 59, 2020
} 
constantemente. A realidade muda e o saber que construímos sobre ela precisa ser revisto e ampliado sempre" (CHRISTOV, 2012, p. 9-10). De acordo com Fávero e Tonieto (2010, p. 56), a formação continuada “[...] acontece por meio da inserção desse profissional no conjunto de conhecimentos que dizem respeito ao seu campo de atuação e visa à construção permanente do 'ser professor"'.

Para Christov (2012), o êxito da formação continuada fortalece-se pela reflexão sobre a prática, principalmente quando se almeja a transformação da prática pedagógica e a construção da autonomia intelectual dos docentes. A formação continuada, desse modo, fortalece-se quando o profissional consegue entender os fenômenos que se entrecruzam na prática docente, projetando novas possibilidades de ser e de atuar como professor (FÁVERO e TONIETO, 2010).

Com base nestas concepções, compreende-se que quando o profissional busca formação por deliberação própria, ela reveste-se de expectativas de ordem prática ou teórica. As "expectativas" representam aquilo que cada um espera de algo, a esperança de conseguir realizar melhor aquilo que faz, a possibilidade de aprender e/ou aperfeiçoar o fazer da função. Neste tópico, analisam-se as expectativas atendidas e as contribuições do processo formativo ao trabalho do coordenador. Conforme Freire (1987, p. 101, grifos do autor), assevera-se que "[...] a superação não se faz no ato de consumir ideias, mas no de produzi-las e de transformá-las na ação e na comunicação. [...]. Os homens são porque estão em relação".

Ao afirmar que as expectativas em relação ao curso foram alcançadas, os coordenadores destacam, como relevante, a troca de experiências com os docentes da universidade e entre o próprio grupo, enfatizando que os temas tratados auxiliam no desempenho do $\mathrm{CP}$ na escola. As respostas dão conta de que houve maior clareza sobre o trabalho do $\mathrm{CP}$, indicando novas alternativas para a dinamização da coordenação na escola. Tais aspectos 
encontram eco nos registros de dezessete coordenadores, dos quais destacamos três:

[...] houve bom relacionamento com o grupo e a universidade, troca de experiências $e$ os assuntos discutidos foram de extrema importância para o bom desempenho do coordenador no ambiente escolar $(C P 1)^{2}$.

O curso esclareceu sobre o papel do coordenador, pois se faz muita coisa que não é nosso papel, deixando de lado o que é essencial na parte pedagógica (CP 8).

Esclareceu, especialmente as atribuições e ações que são incumbência do $C P$ numa instituição de ensino (CP 5).

A reflexão sobre as falas reforça a imprescindibilidade de formação continuada aos profissionais da educação, para ampliar a visão do e sobre o campo de atuação do coordenador pedagógico. Para Placco e Silva (2009, p. 29-30), a ação coordenadora necessita manter “[...] articulação com as formas de organização do mundo escolar, compreendendo que essas formas de organização ganham visibilidade singular no campo do planejamento curricular, da avaliação, das interações mantidas por professores e alunos, [...]". A despeito disso, cabe ao coordenador atentar para a singularidade da comunidade escolar, sem descuidar que os ideários filosóficos, que subsidiam o projeto político-pedagógico, estejam alinhados com a proposta de formação continuada de docentes na escola.

Entre as expectativas a partir do curso, a ampla maioria manifestou-se de que houve a possibilidade de: revisar o trabalho que o coordenador realiza na escola; identificar "equívocos" ocorridos no trabalho da coordenação; repensar as ações no campo da função; obter maior segurança para desenvolver o trabalho; sair do "achismo" para atuar com base em argumentos teóricos referentes à coordenação pedagógica. Isso está referendado nos registros destacados de quatro cursistas abaixo:

\footnotetext{
2 Os instrumentos foram numerados conforme a ordem de entrega. Para manter o anonimato, as citações de trechos de registros constantes no instrumento, adota-se a denominação CP 1, CP 2, CP 3, etc.

Interfaces da Educ., Paranaíba, v.11, n.32, p. 34 - 59, 2020
} 
[...] consegui aprender a identificar erros ocorridos no meu próprio trabalho na escola (CP 7).

Consegui sanar dúvidas e repensar algumas ações; tornou mais clara $e$ compreensiva minha função como CP (CP 11).

[...] apesar de ajudar na escola em tudo, agora sei qual o meu papel e, no próximo ano, vou desenvolver meu trabalho com mais segurança (CP 12).

[...] construí fundamentação teórica para sair do "achismo", tendo uma base que sustente os argumentos para o trabalho na coordenação na escola (CP 15).

A riqueza dos registros aponta que, de algum modo, aconteceu o aperfeiçoamento dos coordenadores, que indicam a relevância de compreender as atribuições para desenvolver o seu trabalho na escola. $\mathrm{Na}$ dinamização da ação coordenadora, pode-se potencializar a prática pedagógica do coletivo escolar. Para tanto, "[...] nunca é demais enfatizar a importância dessa função para a criação e manutenção de um bom nível de ensino, entendido este como a orientação da aprendizagem vivenciada essencialmente pelos sujeitos do processo" (VILLAS BOAS, 2006, p. 66). A prática coordenadora reveste-se de relevância quando articula as ações junto aos docentes para o enfrentamento das situações complexas relacionadas aos processos formativos, que envolvem dois atos distintos - o ensinar e o aprender -, os quais não se efetivam apenas com a utilização de procedimentos e técnicas.

Para coordenadores, a relevância do processo formativo destaca-se também pelo fato de: aprimorar a compreensão sobre como realizar a formação continuada na escola; organizar e coordenar as formações, os tempos e os espaços na escola; repensar e planejar as ações, contribuindo com o processo ensino-aprendizagem; melhorar a formação profissional, tendo clareza das atribuições do CP. Tais aspectos descritos encontram reforço nos registros de quatro dos vinte e um coordenadores cursistas:

[...] compreendi o aspecto da formação continuada, as maneiras de fazê-la na própria escola, estudando e aprofundando assuntos que há necessidade na escola (CP. 21).

Interfaces da Educ., Paranaíba, v.11, n.32, p. 34 - 59, 2020 
[...] repensar e planejar as ações de maneira a contribuir no processo de ensinoaprendizagem e nas interações com a comunidade (CP 19).

Organizar e coordenar as formações, os tempos e espaços escolares (CP. 17).

Uma formação profissional que esclareceu as principais funções do coordenador pedagógico nas escolas (CP 20).

Entende-se que as ações de formação continuada realizadas neste curso de Extensão favoreceram o reconhecimento, por parte dos profissionais da educação, da necessidade de investir em formações, que contribuam com o fortalecimento da autonomia, da criatividade, da reflexão crítica sobre a própria prática. Conforme Christov (2012), em sua atuação, o $\mathrm{CP}$ necessita: conhecer o contexto em que a escola insere-se; ter ciência que ele não é o único responsável pelas transformações na escola; visualizar ações passiveis de concretização. Para tanto, é mister ter em vista o conjunto de relações que concorrem para que as mudanças concretizem-se ou não e que há questões que estão para além da vontade política da escola e dos educadores. Enlaçado a isso, são imprescindiveis adequadas condições de trabalho, recursos financeiros e envolvimento individual e coletivo dos atores educacionais da escola.

Ao tratar da compreensão acerca da função do $\mathrm{CP}$ na escola, os coordenadores ao refletir e avaliar as contribuições da formação explicitam:

- foi importante conhecer o trabalho de outros colegas coordenadores;

- as angústias do grupo de coordenadores são parecidas, eles compreendem as atribuições da função, mas, na escola, atendem outros quefazeres;

- o curso foi relevante para qualificar e aperfeiçoar a identidade profissional de quem assume a coordenação pedagógica;

- o coordenador precisa ser aliado dos professores, ser liderança que contribui na organização e funcionamento da escola;

- o coordenador precisa contribuir com o processo ensinoaprendizagem, atuando junto aos professores, à equipe diretiva e aos alunos. 
$\mathrm{Na}$ reflexão destes depoimentos, é indispensável considerar que a interação entre os pares das diferentes escolas permite, por meio da "catarse" coletiva, filtrar os aspectos significativos e os frágeis no exercício da função. Ancorados na ideia de que os aprendizados constroem-se na relação entre sujeitos - processo relacional -, os coordenadores em relação construíram saberes que, conforme cada realidade escolar permite redimensionar a prática coordenadora. As experiências mesmo diferentes e singulares estão eivadas por saberes que necessitam ser colocados em diálogo com as dimensões: pedagógica e política, que se refletem na intencionalidade e no compromisso com a emancipação dos sujeitos.

Neste sentido, o ideário democrático não permite a interferência de nenhuma forma de intimidação, maniqueísmo, silenciamento, dogmatismo (VILLAS BOAS, 2006). Assim, as ações dos coordenadores pedagógicos, por não serem revestidas de neutralidade, "precisam entrecruzar-se com a totalidade da dinâmica escolar, tendo como foco a transformação das práticas escolares, que requerem reconfiguração e ressignificação" (SARTORI e PAGLIARIN, 2016, p. 196).

A relação entre qualificação/aperfeiçoamento e identidade profissional do coordenador alimenta-se por intermédio das e nas exigências da comunidade escolar para dinamizar o processo pedagógico. O CP ainda engatinha na busca da identidade para a função e o reconhecimento do seu espaço, tanto nos sistemas de ensino como nas escolas. O trabalho na escola é dinâmico, diuturnamente, apresenta novas emergências para as quais é preciso, de forma democrática, debater, encaminhar e realizar as ações com vistas a, no limite das possibilidades, solucionar as situações-problema. Partindo do pressuposto que o coordenador necessita orientar suas ações por meio de relações democráticas: "A co-laboração como característica da ação dialógica, que não pode dar-se a não ser entre sujeitos, ainda que tenham níveis distintos de função, portanto, de responsabilidade, somente Interfaces da Educ., Paranaíba, v.11, n.32, p. 34 - 59, 2020 
pode realizar-se na comunicação" (FREIRE, 1987, p. 166). Tal pressuposto é fundamental e justifica a necessidade de pensar a formação continuada do coordenador pedagógico como processo, não como treinamento técnico.

\section{Formação continuada do coordenador pedagógico: aspectos significativos do curso}

Para abordar os aspectos significativos do curso: Formação continuada para coordenadores pedagógicos é fundamental situar o formato do curso. A participação foi espontânea (decisão pessoal), com o apoio da $15^{\mathrm{a}} \mathrm{CRE}$, que divulgou o curso nas escolas. No primeiro encontro, apresentou-se a proposta do curso e distribuiu-se o material encadernado para os 15 encontros. Os participantes foram organizados em grupos, cada grupo ficou responsável pela dinamização de um encontro. Ainda, neste primeiro encontro, assistiu-se a uma entrevista com Beatriz Gouveia ${ }^{3}$, a qual trata dos dilemas da rotina do Coordenador Pedagógico na escola e, de forma expositiva, situou-se a função de $\mathrm{CP}$ ao longo da história da educação brasileira.

Em cada encontro, além do coordenador do projeto, houve a participação de outro professor da UFFS/Campus Erechim. Houve algumas resistências ao iniciar o curso, especialmente sobre a mobilização dos grupos para organizar as apresentações, realizar registros para a leitura ao iniciar o encontro subsequente, aceitar a ideia de elaborar, ao final do curso, um plano para a ação coordenadora na escola. Destaca-se isso pela explicitação na fala de uma coordenadora "eu não vim aqui para preparar aula (apresentação), eu vim para assistir aulas”. Em contraponto a esta fala, buscou-se, com argumentos, convencer que, no curso, a interação dos

\footnotetext{
${ }^{3}$ Entrevista com Beatriz Gouveia, formadora de Coordenadores Pedagógicos e Assessora de Redes Municipais de Ensino. www.youtube.com/watch?v=-O1jD5wViZc.
}

Interfaces da Educ., Paranaíba, v.11, n.32, p. 34 - 59, 2020 
envolvidos é necessária, pois a proposta não consiste num conjunto de palestras.

Ressalta-se também o desafio de envolver e manter o grupo sintonizado nos debates das temáticas em pauta, havendo constantes desvios por meio de discursos pessimistas e/ou fatalistas do tipo: "já tentamos, mas os professores não assumem", "os professores participam das decisões do coletivo, mas depois agem à revelia", "os professores não se dispõem a estudar", "os professores dizem que não adianta propor algo diferente porque os alunos não querem nada com nada", "sempre foi assim nunca vai mudar", entre outros. Nesta perspectiva, Christov (2012, p. 12) refere que "[...] precisamos construir novas bases para pensar e para intervir nas escolas. Essa construção tem no coordenador um agente fundamental para garantir que os momentos de encontro na escola sejam proveitosos". Segundo a autora, é essencial reorganizar tempos e espaços na escola para refletir, (re)planejar e (re)encaminhar a prática pedagógica.

Os processos formativos sempre engendram intencionalidades $\mathrm{e}$ propósitos, portanto, pautados pela não neutralidade, haja vista que se orientam e expressam determinado viés político e ideológico. Desse modo, a atuação do $\mathrm{CP}$ precisa estar embasada em teorias, que deem relevância à função coordenadora na escola, sendo imprescindivel que sua atuação esteja eivada pelos princípios democráticos do diálogo, da participação e da corresponsabilidade. Em tempo, assinala-se que nem sempre as intencionalidades propositivas e proativas, tanto teóricas como práticas, realizam-se plenamente. Para isso, o feedback com os sujeitos que passaram pela experiência formativa poderá dar a noção daquilo que foi significativo na trajetória. Entre vários aspectos do curso, buscou-se elementos, por meio do questionário, sobre as impressões significativas dos cursistas, que lidas e relidas, permitiram categorizá-las: em relação ao curso (proposta), às experiências e aos aprendizados. 
Quadro 1 - Aspectos significativos: Formação continuada dos coordenadores pedagógicos

\begin{tabular}{|c|c|c|}
\hline Do curso & Das experiências & Dos aprendizados \\
\hline Proposta do curso clara & \begin{tabular}{|lll}
$\begin{array}{l}\text { Convivência } \\
\text { colegas }\end{array}$ & com os \\
\end{tabular} & $\begin{array}{l}\text { Conhecimentos teórico- } \\
\text { práticos }\end{array}$ \\
\hline $\begin{array}{l}\text { Metodologia } \\
\text { organização }\end{array}$ & Troca de experiências & Foco na função do CP \\
\hline Escolha dos temas & $\begin{array}{l}\text { Espaço para relatar } \\
\text { experiências }\end{array}$ & $\begin{array}{l}\text { Relação teoria e prática } \\
\text { - práxis }\end{array}$ \\
\hline $\begin{array}{l}\text { Distribuição de tarefas } \\
\text { aos cursistas }\end{array}$ & $\begin{array}{l}\text { Discussões embasadas } \\
\text { nas leituras }\end{array}$ & $\begin{array}{l}\text { Atuação junto aos } \\
\text { professores, articulando } \\
\text { o processo ensino- } \\
\text { aprendizagem do aluno }\end{array}$ \\
\hline Cronograma fixo & $\begin{array}{l}\text { Reflexão sobre a própria } \\
\text { prática }\end{array}$ & $\begin{array}{l}\text { Aprofundamento teórico } \\
\text { sobre o trabalho do } \mathrm{CP}\end{array}$ \\
\hline $\begin{array}{l}\text { Material encadernado } \\
\text { com os textos do curso }\end{array}$ & $\begin{array}{l}\text { Relatos de colegas } \\
\text { experientes na função }\end{array}$ & $\begin{array}{lr}\text { Formação } & \text { continuada } \\
\text { na escola, } & \text { tratando } \\
\text { problemáticas } & \text { do } \\
\text { cotidiano } & \end{array}$ \\
\hline $\begin{array}{l}\text { Problematização } \\
\text { constante da realidade } \\
\text { da escola }\end{array}$ & $\begin{array}{l}\text { Olhar diferente para } \\
\text { atuação como CP }\end{array}$ & $\begin{array}{l}\text { Relação da avaliação } \\
\text { com o conselho de } \\
\text { classe }\end{array}$ \\
\hline $\begin{array}{l}\text { Apresentação } \\
\text { grupos }\end{array}$ & $\begin{array}{l}\text { Interação: professores } \\
\text { da UFFS } \\
\text { coordenadores }\end{array}$ & $\begin{array}{ll}\text { Compreensão } & \text { da } \\
\text { função-articulação do } \\
\mathrm{CP} \text { com a equipe } \\
\text { diretiva }\end{array}$ \\
\hline $\begin{array}{l}\text { Sugestões para a } \\
\text { organização do trabalho } \\
\text { do CP na escola }\end{array}$ & $\begin{array}{l}\text { Contribuição } \\
\text { desempenho da função }\end{array}$ & $\begin{array}{l}\text { Relações interpessoais } \\
\text { no cotidiano escolar }\end{array}$ \\
\hline
\end{tabular}

Fonte: Questionários respondidos pelos coordenadores/cursistas.

Tendo em vista a indicação dos aspectos significativos, tecem-se algumas incursões interpretativas e inferenciais aos leitores deste estudo. No que tange às impressões relacionadas ao curso, a valoração da proposta e da metodologia deveu-se ao fato de a proposta estar marcada pela necessidade 
de empenho, seriedade e compromisso dos participantes. Na organização da proposta, foram buscadas temáticas que se articulassem com o espaço escolar, com a organização do processo pedagógico e com os sujeitos envolvidos (diretor, coordenador pedagógico, orientador educacional e docentes).

Para promover a interação e chamar ao compromisso com o curso, todos foram incluídos em um grupo com a responsabilidade do preparo e apresentação aos cursistas de um dos temas indicados. Aos grupos foi dada a liberdade para preparar sua apresentação, podendo, além dos textos, ancorar-se em outros estudos e recursos afetos a sua temática. O fato de o "cronograma fixo" ser indicado como um dos pontos positivos relaciona-se à possibilidade de terem conseguido organizar-se na escola para afastar-se e participar da formação. Sem dúvida, o afastamento do CP gera necessidade de outro profissional, que, conforme Villas Boas (2006) requer "espírito de coparticipação", o que facilita os ajustes indispensáveis ao trabalho educativo na escola.

A problematização e a complexidade que atravessam o fenômeno educativo, os quefazeres da escola e as relações interpessoais que coabitam o espaço escolar representam meios para questionar realizações, processos e resultados. A problematização, como recurso pedagógico, é um procedimento, que torna viva e motivadora a participação, com possibilidade de incorporar, nos debates, experiências, saberes e fazeres afetos ao trabalho do CP. Neste aspecto, o efeito interativo entre os sujeitos é mobilizador das energias entre os docentes em prol dos objetivos educacionais que perseguem (VILLAS BOAS, 2006).

Ao trazer a convivência com colegas coordenadores, a troca de experiências, as discussões orientadas pelos textos, os relatos de coordenadores experientes, os cursistas reforçam que o aspecto relacional é promotor de aprendizados. Neste sentido, a socialização das situaçõesInterfaces da Educ., Paranaíba, v.11, n.32, p. 34 - 59, 2020 
problema que pulsam na escola mobiliza a reflexão e a reconstrução da prática profissional, que não prescinde do princípio freireano da açãoreflexão-ação. De acordo com Fávero e Tonieto (2010, p. 63):

\footnotetext{
O exercício profissional do professor $[\mathrm{CP}]$ requer algo além dos conhecimentos técnicos e científicos subjacentes à sua profissionalidade; requer, na verdade, que ele seja capaz de refletir para transformar a sua prática, o seu espaço de ação, em espaço de produção de conhecimentos e construção profissional.
}

Neste sentido, os registros referenciam que o curso contribuiu para aprimorar e revisitar a atuação e o desempenho na coordenação, indicando que a formação ofereceu condições para a reflexão sobre a própria prática. Com base em estudos de Placco e Silva (2009), infere-se que os processos formativos possibilitam ao profissional assumir novas maneiras para enfrentar a dinâmica das mudanças sociais, que demandam a reconfiguração de objetivos, metodologias, práticas pedagógicas. Para isso, o empoderamento teórico é essencial, pois, conforme Freire (1987), é no encontro com a teoria que cada sujeito pode construir a sua libertação, tendo em vista que a teoria faz-se e se re-faz ao dialogar com a prática.

Os coordenadores indicam a interação entre eles e os professores da UFFS como importante, puderam relatar suas experiências e posicionaremse durante os debates e os momentos de aprofundamento teórico. É fundamental entender que a educação caracteriza-se como prática social e estabelece laços estreitos entre sujeitos e instituições envolvidos em processos educativos formais. Intenciona-se que a formação embasada em intencionalidades auxilie o desenvolvimento cognitivo e socioafetivo, favorecendo o diálogo intersubjetivo e a ampliação da visão de mundo, de sociedade, de escola e do processo ensino-aprendizagem. Segundo Christov (2012), esta visão não pode mais ser escamoteada, tampouco enquadrada em uma chave de compreensão, mas substituída por visões que abarquem a complexidade e a dinâmica das relações, das trajetórias e das realidades socioeducacionais.

Interfaces da Educ., Paranaíba, v.11, n.32, p. 34 - 59, 2020 
Em conexão com o processo formativo realizado, os aprendizados recaem sobre: os conhecimentos práticos relativos à função na coordenação pedagógica; a atuação junto aos docentes com olhar voltado ao processo ensino-aprendizagem do aluno; a relação entre teoria e prática; a avaliação e sua articulação com o conselho de classe; as relações interpessoais no ambiente escolar. Compreende-se que os aprendizados elencados, por si só, não resolvem todas as mazelas do cotidiano escolar, pois o $\mathrm{CP}$ não é o único responsável pela efetivação do processo educativo na escola. Por sua vez, a formação continuada realizada na própria escola pode desencadear "[...] estratégias que se articulem às necessidades que emergem do e no contexto escolar, de modo a integrar, por meio da prática reflexiva e do trabalho coletivo, formas de intervenção e, consequentemente, de transformação da prática pedagógica" (SARTORI \& PAGLIARIN, 2016, p. 199, grifo dos autores).

À potencialização do trabalho do $\mathrm{CP}$ é fundamental mobilizar a organização e o funcionamento da escola, articulados com a dinamização do processo pedagógico do professor em sala de aula. Nesse encadeamento, Fávero e Tonieto (2010, p. 63) asseveram

[...] que o bom professor é aquele que é capaz de articular, em seu trabalho pedagógico, duas instâncias básicas: a do conhecimento elaborado (teoria) e a da prática (espaço de ação), de modo a superar um pensamento técnico de aplicação e assumir uma postura de criação reflexiva e inteligente.

Sendo que a ação coordenadora está (deveria estar) sempre voltada para o processo ensino-aprendizagem que se realiza na escola, é primordial o investimento na assessoria ao planejamento e ao desenvolvimento da prática docente, favorecendo a reflexão crítica sobre as dificuldades que se entrecruzam no trabalho pedagógico. 


\section{Coordenador pedagógico: o trabalho na escola}

Tecer críticas acerca do trabalho do $\mathrm{CP}$ requer cautela, pois, na prática coordenadora, estão implicadas diferentes concepções, variando desde a formação até as condições de trabalho deste profissional. A formação inicial é condição para ingressar na carreira do magistério, já para atuar na coordenação pedagógica, segundo a LDB - Lei n ${ }^{\circ}$ 9394/96 - art. 64, a formação indicada é licenciatura em Pedagogia ou em curso de pósgraduação lato sensu. Como os sistemas têm autonomia, não há impedimento para que graduados em qualquer licenciatura, mesmo sem especialização, assumam a função coordenadora. Neste sentido, pondera-se que a formação continuada torna-se indispensável ao aperfeiçoamento do trabalho do coordenador. Além disso, o exercício da coordenação requer condições adequadas de trabalho, especialmente, espaço e tempo para dedicar-se à essencialidade dos fazeres do setor pedagógico.

Nesse tópico do estudo, analisa-se, conforme os registros no instrumento questionário, a forma como o trabalho do CP é concretizado na escola e como o plano de ação do coordenador contribui para o êxito em suas atividades. Em relação ao trabalho dos coordenadores na escola, fica claro o desvio do foco da função por terem que: substituir professores faltantes; entregar material aos professores; solucionar problemas de indisciplina; auxiliar no trabalho administrativo da escola; atender pais; efetuar registros nas agendas; servir como "bombeiro para apagar os incêndios". Há, pois, aqueles que realizam um trabalho de mediação para facilitar a atuação docente na dinamização de suas aulas. Tais aspectos podem ser observados nos registros:

[...] o trabalho do CP é de tentar solucionar problemas como: substituir professores, entregar material aos professores, problemas de disciplina dos alunos (CP 8).

[...] realiza atendimentos aos pais, passa recados nas agendas, encaminha alunos para o dentista e posto de saúde, orienta o serviço de limpeza da escola (CP 19). 
[...] ajuda no administrativo e serve de "bombeiro para apagar incêndios" (CP 13).

No meu trabalho faço a mediação para facilitar o desenvolvimento das atividades docentes, oferecendo sugestões para dinamizar as aulas (CP 4).

É preciso conhecer a realidade da escola para não incorrer no risco de culpabilizar os profissionais da educação, tampouco a escola, pois há situações que requerem a interferência e o investimento das mantenedoras (Estados ou Municípios), especialmente, no que tange ao quadro de pessoal necessário ao bom funcionamento dos setores da escola. Não se trata de negligenciar as atividades realizadas pelo CP desfocadas de suas atribuições, mas "[...] entendemos que tais ações/serviços deveriam ou devem ser cumpridos pela escola, mas por outros profissionais da área técnica, administrativa ou mesmo pedagógica" (SARTORI \& PAGLIARIN, 2016, p. 199). Sem dúvida, a função coordenadora necessita, em alguns espaços, ser ressignificada para que o foco do trabalho seja a mobilização dos docentes para o fortalecimento dos processos pedagógicos em vista da melhoria da qualidade do ensino.

Em relação ao trabalho de mediador alinhado com as atribuições do $\mathrm{CP}$, destaca-se que o ato de mediar inclui a mobilização dos quefazeres pedagógicos, que envolvem coordenador e coordenados. É, pois, pelo diálogo, que se pode mobilizar para adesão que "[...] é a coincidência livre de opções. Não pode verificar-se a não ser na intercomunicação dos homens, mediatizados pela realidade" (FREIRE, 1987, p. 167). Para o referido autor, é pela ação dialógica que os sujeitos atentam para "[...] a realidade mediadora que, problematizada, os desafia” para transformá-la (ibidem, p. 167).

É indispensável ao CP que ao exercer sua função tenha o "plano de ação", por duas razões: primeira, porque todo o trabalho que expressa intencionalidades precisa de planejamento para orientar as ações; segunda, porque cabe ao $\mathrm{CP}$ exigir dos docentes a elaboração e entrega do plano de ensino, sendo contraditório exigir do docente e o coordenador dispensar-se Interfaces da Educ., Paranaíba, v.11, n.32, p. 34 - 59, 2020 
de elaborar seu plano. A exigência do planejamento, tanto dos docentes quanto do coordenador evite a "improvisação docente" que frequentemente acontece no cenário de precarização das condições de trabalho e de formação aligeirada. Como ressaltam Fávero e Tonieto (2015, p.24) em estudo recente, a improvisação indica "um sinal de alerta sobre as condições precárias como muitos se tornam professores sem as mínimas condições de formação pedagógica".

Nos escritos dos coordenadores, fica tácito que o plano de ação: norteia o processo; facilita o desempenho da função com êxito; é imprescindivel para que o coordenador consiga trabalhar na perspectiva da reflexão sobre sua prática; ajuda na organização e na orientação do trabalho; orienta as ações que efetivamente fazem parte do rol de atribuições do CP. Tais questões estão referendadas nos registros destacados:

[...] plano de ação norteia o processo, mostra aos colegas os objetivos para atingir com o comprometimento de todos (CP 4).

[...] o plano de ação é imprescindivel para que o coordenador trabalhe numa perspectiva de reflexão da sua prática (CP 15).

[...] o plano de ação orienta na realização das ações que são de responsabilidade do coordenador na escola (CP. 14).

A discussão sobre planejamento é antiga e ao mesmo tempo atual, haja vista que, como instrumento de ação, o planejamento embasa a organização e o desenvolvimento da prática pedagógica. Expresso em outros termos, o planejamento representa uma necessidade em qualquer ação que envolva processos educativos formais, seja na gestão ou na docência, viabiliza o ordenamento de meios para alcançar os fins.

No ato de planejar, indicam-se objetivos, procedimentos metodológicos e de avaliação das ações. Ao ter em conta que avaliar consiste em dialogar com os objetivos, com os procedimentos, com os processos e com os resultados, é necessário ir além do viés pragmático e técnico. Assim sendo, se o contexto revela-se complexo, é primordial questionar os resultados sem desconsiderar, na análise, as bases epistemológicas, em que se ancoram os Interfaces da Educ., Paranaíba, v.11, n.32, p. 34 - 59, 2020 
procedimentos que geraram os processos e, consequentemente, produziram os resultados. Ao olhar pelo ângulo da relação teoria e prática - da práxis - e refletir sobre o feito/realizado é que se pode redimensionar e projetar um novo agir e/ou uma nova ação.

Desse modo, entende-se como desafio ao planejamento do CP a criação de ações capazes de mobilizar o profissional da educação à prática reflexiva, que oriente novas práticas com base na análise daquelas já concretizadas. Conforme Fávero e Tonieto (2010), a incitação colocada aos processos formativos é a de mobilizar mecanismos, que permitam compreender a dimensão ética e política do profissional da educação, para que se reconheça compromissado pedagogicamente com os fins da educação.

A relevância do trabalho do coordenador pedagógico ganha notoriedade pelos desafios que compõem a tessitura do contexto socioeducacional. A responsabilidade de realizar a gestão do processo pedagógico na escola requer que o $\mathrm{CP}$ foque seu trabalho no essencial e não no acidental. Além disso, o trabalho do $\mathrm{CP}$ demanda clima de mútua confiança entre os diferentes atores, que convivem no espaço escolar. Ao cultivar um ambiente amistoso e democrático de trabalho, o movimento na escola faz-se e refaz-se continuamente, por isso, os profissionais da educação como seres históricos estão necessariamente num movimento de busca, de formar e de formar-se (FREIRE, 1987). Por fim, enfatiza-se que a ação coordenadora encharcada de intencionalidades, eivada por princípios democráticos que buscam conduzir as ações de forma colaborativa necessita ser planejada.

\section{Considerações finais}

Ao entrelaçar considerações sobre o estudo, explicita-se o olhar de um ponto de vista e de alguns pressupostos teóricos, para o que outro olhar possa filtrar outros aspectos e atribuir outros significados. Com a clareza da 
provisoriedade e dos limites desta análise da formação continuada de coordenadores pedagógicos da região da $15^{\mathrm{a}} \mathrm{CRE}$ - Erechim, realizada em 2018-2019, as reflexões estiveram balizadas em concepções que orientam os processos de formação continuada, o trabalho do coordenador pedagógico e a organização e dinamização do espaço escolar.

Com olhar atento à questão e ao objetivo de estudo, com fidedignidade aos dados produzidos por meio do questionário, infere-se um olhar critico, ao mesmo tempo aberto a outras possíveis análises. $\mathrm{Na}$ tentativa de argumentar sobre como o processo formativo contribuiu com o fortalecimento da ação coordenadora na escola, aponta-se que a troca de experiências entre os coordenadores foi significativa para o ato de repensar o trabalho do CP na escola. Há entre os coordenadores a consciência das frágeis condições em que realizam suas funções, contudo, é imprescindivel avançar do nível da consciência e assumir uma atitude "revolucionária". De acordo com Freire (1987, p. 74), o ato revolucionário contrapõe-se à educação bancária, bem como a todas as formas de opressão, colocando os diferentes atores em movimento de busca da autonomia e da humanização dos homens, por isso, "[...] enquanto viabilidade, deve aparecer aos homens como desafio e não como freio ao ato de buscar".

No movimento dialético, problematiza-se, produz-se consciência e alternativas ao enfrentamento às situações-problema que afetam o exercício profissional do coordenador. Entende-se que é, a partir da mobilização dos coordenadores, tensionando as direções e as mantenedoras, que eles podem encontrar saídas para melhorar as condições de trabalho, que lhes permitam focar na essencialidade de suas funções, deixando de ser o "apagador de incêndios" ou "pau para toda obra" na escola.

$\mathrm{O}$ trabalho do $\mathrm{CP}$ na gestão e na dinamização do processo pedagógico requer espaço, tempo, compromisso e pré-disposição para liderar e mediar os sujeitos na relação com o projeto educativo da escola. A instigação que se coloca ao coordenador é a de estabelecer, com seus pares, um diálogo franco 
e aberto sobre as problemáticas que se entrecruzam na prática docente, de modo que "não é no silêncio que os homens se fazem, mas na palavra, no trabalho, na ação-reflexão" (FREIRE, 1987, p. 78).

Pelo estudo realizado, destaca-se, segundo os cursistas, que a formação continuada com a perspectiva, não única, de formar por meio de um processo que possibilite referências e parâmetros (PLACCO \& SILVA, 2009) não pode deixar-se seduzir por modelos, mas por meio de uma matriz teórica flexível, que favorece adequações aos diferentes momentos e realidades. Assim sendo, o ato de formar e de formar-se no movimento do exercício profissional favorece assumir uma posição crítica em relação à pluralidade de ações e subjetivações na formação do profissional da educação. Dessa forma, os processos formativos sob a responsabilidade do coordenador estão vinculados diretamente às problemáticas que eclodem no dia a dia no "chão" da escola. Então, cabe ao CP o trabalho de assessorar o professor, para que ele aprimore seus conhecimentos e potencialize sua prática pedagógica, fomentando o desenvolvimento do processo ensinoaprendizagem em sala de aula.

Por fim, destaca-se que se todo o professor tem o papel social de ser transformador, então, o CP precisa enfrentar os desafios e tornar-se o protagonista da formação continuada na escola, buscando atuar de forma participativa, colaborativa, democrática numa relação respeitosa e de parceria, em que o trabalho dele (coordenador) seja realizado com e não para os docentes.

\section{Referências:}

BARDIN, Laurence. Análise de Conteúdo. Lisboa: Edições 70, 1977.

BRASIL. Lei n. 9394/96. Estabelece as diretrizes a bases da educação nacional. Brasília. 1996. 
BRASIL. Lei $n$. 5692/71. Estabelece as diretrizes para o ensino de $1^{\circ}$ e $2^{\circ}$ graus. Brasília, 1971.

BRASIL. Lei n. 5540/68. Fixa normas de organização e funcionamento do ensino superior e sua articulação com a escola média. Brasília, 1968.

BRASIL. Lei de Diretrizes e Bases - Lei 4024/61. Disponivel em:

https://jus.com.br/artigos/21145/a-lei-do-piso-e-a-jornada-do-professor. Acesso em: 20 ago. 2019.

BRASIL. Conselho Federal de Educação. Parecer n. 252/ 1969. Disponivel em: https://www.passeidireto.com/arquivo/parecer 252. Acesso em: 10 set. 2019.

CHRISTOV, L. H. da S. Educação continuada: função essencial do coordenador pedagógico. In: GUIMARÃES, A. A. et al. O coordenador pedagógicos e a educação continuada. 14. ed. São Paulo: Loyola, 2012. p. 913.

FÁVERO, A. A. \& TONIETO, C. Criatividade não é improvisação: critica a uma concepção equivocada de docência universitária. In: FÁVERO, A. A. \& TONIETO, C. (orgs.). Docência universitária: pressupostos teóricos e perspectivas didáticas. Campinas: Mercado de Letras, 2015. p. 17-36

FÁVERO, A. A. \& TONIETO, C. Educar o educador: reflexões sobre a formação docente. Campinas, SP: Mercado de Letras, 2010.

FREIRE, Paulo. Pedagogia do Oprimido. 17. ed. Rio de Janeiro: Paz e Terra, 1987.

PLACCO, V. M. N. de S. \& SILVA, S. H. S. da. A formação do professor: reflexões, desafios, perspectivas. In: BRUNO, E. B. G.; ALMEIDA, L. R. de; CHRISTOV, Luiza H. da S. (orgs.). O coordenador pedagógico e a formação docente. São Paulo: Loyola, 2009, p. 25-32.

PRZYBYLSKI, E. Supervisão Escolar: concepções básicas. Porto Alegre: Sagra, 1982.

SARTORI, J. \& PAGLIARIN, L. L. P. O coordenador pedagógico: limites e potencialidades ao atuar na educação básica. Espaço Pedagógico. v. 23, n. 1, Passo Fundo, p. 185-204, jan./jun. 2016.

SAVIANI, D. História do tempo e tempo da história: estudos de historiografia e história da educação. Campinas, SP: Autores Associados, 2015.

Interfaces da Educ., Paranaíba, v.11, n.32, p. 34 - 59, 2020 
VILLAS BOAS, M. V. A prática da supervisão. In: ALVES, Nilda (coord.). Educação \& Supervisão: o trabalho coletivo na escola. 11. ed. São Paulo: Cortez, 2006. p. 63-70. 